\title{
Assessing the Bearing Capacity of Cast Laterite in Compression and Flexure
}

\author{
Adeola A Adedeji* \\ Department of Civil Engineering, University of Ilorin, PMB 1515, Ilorin, Nigeria
}

\begin{abstract}
This article examines the usability of the mixture of laterite and calcined (heated) gypsum or cast laterite as a residential building masonry material. The objectives involved preliminary tests to determine the gradation of the laterite, mix ratio of the constituent materials with adequate proportion of heated gypsum. Compressive and flexural tests were carried out on the samples to determine the suitability of the material for walling. The results obtained from this work show that calcined gypsum is suitable for a non-load bearing (infill) masonry material. The comparison of the tests results indicates that cast laterite of $15 \%$ gypsum additive is adequate and higher in compression and flexure than the conventional sandcrete blocks.
\end{abstract}

Key Words: Compressive strength, Flexural strength, Laterite, Gypsum.

\section{INTRODUCTION}

Many materials have been used in civil engineering as building materials which have the ability to resist the imposed load on such structures. The materials used include steel; fine aggregate, coarse aggregate, laterite among others. Due to cost, availability, strength of the materials used, some are preferred to the other. The cheapness and availability of laterite materials makes it have an edge over others. Laterite a natural material has continuously been put to use to build walls which are vertical members forming an enclosure or defining a space to or boundary and are usually required in a building to hold the roof to keep out rain, resist the transmission of heat and sound, resist fire to a reasonable extent, and give protection to the users of such structures. Despite the availability and cheapness of laterite as a building material, the use of the material is gradually fading away due to problems such as shrinkage cracking when trying to pour laterite walls as water slurry, labour intensively involved in ramming laterite or joining blocks together among others. Thus, the invention of cost of cast laterite. Cast laterite is the invention of Harris [1] of Phoenic, Arizona. He grew up in an adobe home living in the southwest and loved the feeling of living in a laterite home. As a chemist, he became fascinated with the idea of making individual adobe blocks for building, or intensively ramming laterite into forms little by little, he wanted to be able to pout the plastic laterite material into a molten form and have it set up very quickly within a day. He started experimenting with adding calcined (heated) gypsum to laterite and found that a fairly small percentage of the gypsum would make a very solid block. This worked fine for very small projects but for larger walls it set up too quickly (within minutes), so he looked for retarding agents that could be added to the mix to slow down the set time. Standard

*Address correspondence to this author at the Department of Civil Engineering, University of Ilorin, PMB 1515, Ilorin, Nigeria;

E-mail: aaadeji@unilorin.edu.ng, gaiadeji@gmail.com retarding agents would only expand the time frame by a few more minutes.

Retarded selection is extremely important, because of drastic strength loss. In developing the technology, powerful retarders which do not seriously reduce strength were discovered. Harris [1] came up with a promising mix that allowed 2 hours of working time and he built his first prototype building using this method in 1995. Cast laterite has some very interesting and useful properties. The compressive strength is about the same as adobe or rammed laterite sufficient to support most conventional building loads. The tensile strength, however, is several times greater than these materials which makes it much stronger and perhaps more durable. Unlike adobe, cast laterite does not shrink as it cures (it actually expands slightly), making it much less likely to crack like other laterite material, it will absorb moisture, but it retains enough strength even when saturated, to maintain its structural integrity, it can be rendered moisture resistant by the use of additives to the original mix or by spraying the finished product with a silica spray. Another major consideration is that cast laterite can be made from a wide variety of types of soil, unlike adobe, rammed laterite and cob (which must have certain percentage of clay to larger soil). Cast laterite does not require the binding capacity of clay. It can utilize soil with some clay in it and unlike cement which cannot tolerate much fine material like clay. Cast laterite can easily incorporate clay into the matrix it operates.

\section{AIMS AND OBJECTIVES}

The aim and objectives include; (i) modelling a cast laterite block comprising laterite and locally available gypsum, (ii) testing and determination of the compressive and flexural strength of the cast laterite block, (iii) comparing the strength result with the already available conventional material for wall construction and (iv) reducing the dependence on cement as binder.

The scope of the project involves the proposed use of laterite and locally available gypsum for the construction of 
wall for residential buildings. The cast laterite block specimens were moulded and the compressive and flexural strength tests were carried out for assessment of the block bearing capacity. The results were compared with sandcrete blocks

\section{HISTORICAL BACKGROUND}

Laterite as a building material has continuously been put to use to build walls. Coupled with the nation's worsening and the declining rate of traditional materials, ways of improving the locally available materials to meet and complete with the modern materials became paramount. Efforts are been placed on the ways in which the cost of residential buildings can be reduced especially through the use of local materials so as to provide shelter for the general populace at an affordable cost. In view of this, research efforts have been geared in recent years towards evaluating the usefulness and improvement of traditional laterite materials in building and allied industries.

This work is based on the assessment of strength and durability of walls built of traditional laterite materials, $\mathrm{Ab}$ dulkareem [2], Medubu [3], in their studies reported that although the durability tests performed in the laboratory on brick size specimen of mud walls and sundried bricks were unsatisfactory, observations made on the field did not portray the situation to be worse. This shows that mud/laterite can still perform the basic function as a wall material. According to [4], the nature of source from where the materials are produced greatly affect the strength of the material as the finer the grain size of the soil, the higher the compressive strength that can be achieved. This implies that it is better to break the lumps that may present before using it.

\section{ORIGIN OF CAST LATERITE}

Harris [1] grew up in an adobe house (an unburnt brick dried in the sun). He appreciated the great quite, subtle power and energy conservation of the massive walls of rammed laterite walls and was sad and nostalgic that the fine laterite structure of the past century is fast loosing popularity and were no longer erected. Lowenhaupt [5] hit on an idea that just might work, after a little laboratory testing; it appeared that a mixture of soil and calcined gypsum showed promise. Three walls were built to prove that the mix would not crack and shrink as it dried. The problem in the past with pouring laterite walls as water slurry had been that shrinkage cracking almost defeated the attempt. Because the gypsum adds strength, prevents shrinkage of clays upon drying and expands slightly when it sets, Shrinkage is not a problem in cast laterite. This was done in the early stages of development via a small hand-loaded concrete mixer, when he had not learned to retard the set of the calcined gypsum binder, and working time as extreme limited. By the years, he has gotten a mix design that would stay open for 15-20 minute and work up enough courage to pour a small prototype wall using machinery instead of hand labour. When the wall showed no sign of cracking and it developed an exiting rich texture as some aggregate were expose, he worked to develop a retarder cocktail which would really open up the mix to make it handles much like concrete. Finally he arrived at a mix that would say workable for over two hours. He thought this as astounding and set about erecting a prototype building after which a lot of buildings have been erected.

\section{WHAT IS CAST LATERITE}

Cast laterite is a structural material made with literate and calcined gypsum. It can replace wood or steel framing in residential and light commercial building yielding energy and environmental benefits. Cast laterite has been demonstrated successfully in residential and commercial structures. It is a true 'breakthrough technology' producing product with all the properties of traditional construction augmented by superior aesthetics, rapid construction and affordable cost. Cast laterite does not involve layed bricks or slowly compacting laterite by mechanical or pneumatic action. Instead, it consists of rapidly pouring entire building walls into a formwork that is removed shortly after the pour. What makes this possible is the ability of calcined gypsum's fast set rate to a wet strength sufficient enough to support a load at low concentration. The low percentage provides surprising strength immediately after setting. Steel reinforcement is not used.

\section{CONSTRUCTION PROCEDURE}

Cast laterite is made with equipment used in the concrete industry; a very useful and versatile piece of equipment used for mixing cast laterite is made concrete mobile mixer. Basically wall forms are set to receive the cast laterite mix by ties. After the mix has set, the form works are stripped for reuse. In most causes, before they are stripped, a reinforced concrete bond beam is poured in the top where it is placed by not leaving a void for the bond beam.

An alternative to the mobile and all the equipment which feeds it are concrete ready mix trucks which operate in conjunction with a nearly batch plants. In this case the pouring remain continuous or nearly so, with a full truck arriving just before a trucks is empty. While the mixing proceeds, iron oxide pigments are added in various combinations to create colour striations in the finished wall.

\section{COMPOSITION OF MATERIAL}

\subsection{Laterite}

Conventional laterite building requires soils containing sand fractions and a smaller fines fraction, which is fairly low in lay content and has a cohesive nature. It is commonly believed that cast (roughly $15-40 \%$ ) must be present to provide cohesion. They are referred to as dead and are not suitable. Because of the cementitous character of gypsum, soils for building with cast laterite are not restricted by a criterion of natural cohesiveness, that property is provided. When the gypsum lattice sets. Thus, a much wider range of soils is available for use. The principal determinant for soil is fine content, which determines the water demand. A certain clay content is acceptable and can benefit cast laterite. The presence of gypsum counteracts the setting for many days to expand and shrink with changing moisture content. The principles in identifying suitable soils for cast laterite are that:

(ii) The largest particles should not exceed $10 \mathrm{~mm}$ and preferably, most of the larger particles should $6 \mathrm{~mm}$ and smaller; and

(ii) The material should contain a range of sizes, varying from the top size to a portion of fines; small particles varying downward from about 100 mesh $(0.006-150 \mathrm{mi}-$ 
crons). The fines should constitute between roughly $10-$ $20 \%$ of the total solid. If the material of this nature is not available, it is often possible to combine to different aggregate to synthesize a soil within the desired range. If one aggregate is too coarse, it can be mixed with another that is quite fine, or if too fine, mixed with some coarse material. Soils with a high salt content should be avoided.

\subsection{Gypsum}

The most common sulphate mineral, characterized by the chemical formula $\mathrm{CaSO}_{4} \cdot 2 \mathrm{H}_{2} \mathrm{O}$, it shows little variations from this composition. Gypsum is one of the most evaporate minerals. This mineral group includes chlorides, carbonates, borates, nitrates and sulphate. These minerals precipitate in seas, lakes, caves and salt flats due to concentration of ions by evaporation. When heated it is subjected to solutions with very large salinities, gypsum converts to bassanite $\left(\mathrm{CaSO}_{4} \cdot \mathrm{H}_{2} \mathrm{O}\right)$ or anhydrite is direct. The conversion occurs above $42^{0} \mathrm{C}$ in pure water. The crystals of gypsum are commonly tubular, diamond-shaped or lenticular; sallow-tailet twins are also common. The mineral is monoclinic with symmetry $2 / \mathrm{m}$ with common colours displayed are white, grey, brown and yellow. Gypsum is the index material chosen for hardness 2 with a specific gravity of 2.32 . In addition to free crystals, the common forms of gypsum are satin spar (fibrous), alabaster (finely crystalline) and selenite (massive crystalline). Gypsum is used for a variety of purposes, but chiefly in the manufacture of plaster of Paris in the production of wallboard, in agriculture to loosen clay-rich soil in the manufacture of fertilizer and also cement.

\subsection{Processing of Gypsum}

To use gypsum for cast laterite, it has to be gently heated calcined. It has cement-like properties, but unlike Portland cement, its strength is not destroyed by fine soil particles. This unique binder allows cast laterite to set rapidly, have sufficient wet strength to support itself, and dry to a much higher strength without cracking and shrinking. Very importantly, it does these things at unexpectedly low gypsum content. What makes the cast laterite process work is the unusual chemistry of gypsum with heat and water. Natural gypsum is a crystal of calcium sulphate in combination with two molecules of water. When it is carefully heated in the process of converting it to calcined gypsum, exactly three fourths of the water is driven off.

$\mathrm{CaSO} \times 2 \mathrm{HO}_{2} \rightarrow \mathrm{CaSO} \times 0.5 \mathrm{HO}_{2}+1.5 \mathrm{HO}_{2}$
The chemical name of the dry product containing one half molecule of water is sulphate hemihydrate referred calcined gypsum in a very pure and milled form. It is the well known Plaster of Paris used in casting, normally at a high concentration and with little if any aggregate. It recombines with the same amount of water lost during and sets to form a strong gypsum crystal lattice.

$$
\mathrm{CaSO}_{4} \times 0.5 \mathrm{H}_{2} \mathrm{O}+1.5 \mathrm{H}_{2} \mathrm{O} \rightarrow \mathrm{CaSO}_{4} \times 0.5 \mathrm{H}_{2} \mathrm{O}
$$

The setting property of calcined gypsum is uncommon and does not occur to such an extent with most other crystals when they rehydrate after loss of water. It imparts a very useful functionality to another common and uninteresting material.

\section{LOCAL OCCURRENCES IN NIGERIA}

Gypsum deposits in Nigeria are formed mainly in small lenticular bodies or lumps sandwiched sedimentary rock formation at or near the surface of the laterite. It occurs in several locations in Nigeria namely Sokoto, Borno, Edo, Delta, Benue, Bauchi, Imo, Abia, Anambra, Enugu, Ogun and Taraba States. Detailed explorations have been carried out only for Sokoto, and Borno deposits. The Sokoto reserve has an estimated 200 million tons while those of Borno/Yobe deposit are estimated at 140 million tons.

It is pertinent to know that while it is true there is enough gypsum deposits in Nigeria to satisfy the existing industries, investigations revealed that some impurities are present in the locally available gypsum that has deleterious effects on the product depending on the usage. The results are shown in Tables $\mathbf{1}$ and $\mathbf{2}$.

\section{COMPRESSIVE STRENGTH}

The compressive strength of building units plays an important role in the durability, stability and average strength of a building. The British standard (BS 6073) [8] stipulates that the compressive strength of sandcrete blocks should be the average of 10 blocks which range between $1.8-2.5 \mathrm{~N} / \mathrm{mm}^{2}$. This implies that manufactures or users must test at least 10 blocks out of every new batch of blocks the manufacturers make for the users to buy.

The strength of building unit is commonly considered the most important property, although in many practical cases, other characteristics such as durability and impermeability may infact be more important. Nevertheless, strength usually gives an overall picture of the quality of the building (here

Table 1. Nigeria's Gypsum Requirements for Cement Production (in MT)

\begin{tabular}{|c|c|c|c|c|c|}
\hline Year & Gypsum for Cement & Other Gypsum Users & National Gypsum Total Needed & Local Gypsum & Short Fall \\
\hline \hline 1996 & 0.202 & 0.065 & 0267 & 0.030 & 0.237 \\
\hline 1997 & 0.202 & 0.065 & 0.310 & 0.030 & 0.280 \\
\hline 1998 & 0.245 & 0.065 & 0.034 & 0.030 & 0.313 \\
\hline Total & 0.725 & 0.195 & 0.920 & 0.830 \\
\hline
\end{tabular}

Source [9]. 
cast laterite), because strength is directly related to the durability of the structure and some other important structures.

\section{FLEXURAL STRENGTH}

According to [1], the flexural strength of cast laterite is considerably greater than that of adobe. One of the objectives of this project is to determine the flexural strength characteristics of cast laterite in consideration as a building material for a residential building.

\section{PRODUCTION AND TESTING OF CAST LAT- ERITE}

Laterite used was obtained from the University of Ilorin campus premises. The laterite was free from tree roots, debris and inorganic material. The laterite was well graded and free salts. It contains particles of wide range of sizes.

\subsection{Preliminary Tests}

Sieve analysis otherwise called particle size distribution was carried out to determine the gradation of the selected sample. Poorly graded laterite for cast earth contains particles of about the same size, while well graded sample pro- vides a cast of higher strength and the test sieves to BS410 [9] was employed.

$1000 \mathrm{~g}$ dry sample was prepared and weighed. Selected sets of sieves were weighed and arranged according to their sizes. Samples were then poured into the topmost sieve, covered and then shaken mechanically through the shaker for 10 minutes. Results obtained were tabulated in Table 3 .

The gypsum used was gotten from West African Portland Cement (WAPCO) Shagamu, Ogun State. The origin source was from Sokoto State. The raw gypsum was mixed with impurities such as clay, shale and soapstone and it was thoroughly washed and well dried. The dried sample was thereafter broken down into smaller particles and then subjected to a temperature of $110^{\circ} \mathrm{C}$ for one hour (calcinations).

Water for cast earth was free from impurities such as suspended solids, organic and matter and salts which may adversely affect the setting, hardening and durability of the mix. This requirement was satisfied by using water that is fit for drinking. Water was then added to a specified mixtures in the amount required to make them workable. According to [1], too little water makes the cast earth to set too fast and

Table 2. The State and Location of Gypsum in Nigeria

\begin{tabular}{|c|c|c|}
\hline S/N & State & Location \\
\hline \hline 1 & Borno/Yobe & Fika, Gubio, Tumi fune, Biu, Potiskum Gadaka \\
\hline 2 & Bauchi & Barwo, Madafa, Mada Malori, Gombe \\
\hline 3 & Abia/Imo & Afikpo, Ameki, Okigwe, Ngwa, Bende, Uburu, Makurdi, Okposi Benue Adoka, Umogidi \\
\hline 4 & Anambra/Enugu & Adani, Awka, Nkalagu, Izza, Abakaliki, Ugwuoba Uzo Uwani \\
\hline 5 & Adamawa/Tarab & Lamija, Ngurore, Numan, Guyuk, Sheleng, Karimu Lmido, Bussa, Ibi, Jiu, Lamja, Ledime Gwellura \\
\hline 6 & Sokoto & Wurmo, Dange, Bungudu, Acida, Gada Goronyo \\
\hline 7 & Ogun & Ifo, Papalanto, Ilaro, Ibeshe Ewekoro \\
\hline 8 & Edo & Agbede, Auchi, Oke-ora, Sabongida-ora \\
\hline
\end{tabular}

Source: $[9,10]$.

Table 3. Results of Sieve Analysis

\begin{tabular}{|c|c|c|c|}
\hline Sieve Size $(\mathbf{m m})$ & Weight Retained $(\mathbf{g})$ & \% Retained & Cummulative \% Passing \\
\hline \hline 12 & - & 13.0 & 87 \\
\hline 8 & 130 & 31.0 & 56 \\
\hline 4.75 & 310 & 16 & 40 \\
\hline 2.36 & 160 & 20.0 & 20 \\
\hline 1.18 & 200 & 0.8 & 19.2 \\
\hline 0.85 & 8 & 6.0 & 13.2 \\
\hline 0.425 & 60 & 1.5 & 11.7 \\
\hline 0.300 & 15 & 2.1 & 9.6 \\
\hline 0.150 & 21 & 0.2 & 9.4 \\
\hline 0.075 & 2 & 9.4 & 0 \\
\hline Pan & 94 & & \\
\hline
\end{tabular}


adding much water takes much time to set, which also reduces the strength.

\subsection{Preparation and Test of Material}

Proportions of the calcined gypsum and laterite were used to specify the calcined gypsum/laterite mix. These batching was done by weight or volume and must be determined carefully in order that the resultant mix the require standard.

In this project work however, batching was done by weight. The mix was made with $10 \%$ \& $15 \%$ of calcined gypsum related to the total dry mix (in order words, ratio 1:10 \& 1:7 respectively. Mixing is done manually by trowel because of the small quantity required for making specimens. The calcined gypsum and laterite were thoroughly mixed, such that no trace of unmixed laterite was found in the mixture before adding water and then thoroughly mixed again. The water calcined gypsum ratio was 1:2.5 In accordance to BS 5628 [6] A wooden mould of inner size $150 \mathrm{~mm}$ $\mathrm{x} 75 \mathrm{~mm} \times 75 \mathrm{~mm}$ was constructed for the purpose of the project and lined with nylon to ease the removal of samples after casting. Due to the nature of cast earth which absorbs moisture. The prism was kept a moist condition for 24 hours before it is sun dried for 7 and 14 days. The geometric relationship between the chosen model and the prototype is provided by the scale factor. The cast earth model was designed to be one-third of the standard $450 \mathrm{~mm} \times 225 \mathrm{~mm} \times 225 \mathrm{~mm}$ standard block; hence a scale factor of 3 was used in this work. The choice of this factor was based on the fact that the flexural test machine cannot take the actual size and also to reduce the cost of the materials. Tests were carried out on the prisms for determining some of its properties which include:

\subsection{Dry Unit Weight and Unit Density}

In the process of determining the densities of the cast earth, their dry unit weight was determined. Weights of five consecutive cast earth blocks were measured with the aid of weighing balance to determine their weight. Cast earth density is the complete dry block unit mass divided by its gross volume. For the cast earth block, this is determined for use in determination of loads in structures and handling requirements. (See Table 4).

\subsection{Compressive Strength of the Blocks}

A testing machine of sufficient capacity for the test and equipped with a means of providing the rate of loading specified with a pacing device was used to test the sample. The machine complied with the requirements of grade $\mathrm{A}$ or B of BS1610: 3.1.1 [7] as regards accuracy.

\subsection{Flexural Strength of the Blocks}

The flexural test was carried out using the universal machine in conjunction with a computer as an output device which was used to determine the deflection of cast earth block from different application of load. The blocks were tested with the flexural testing accessories, which gives the loading values and the deflections of the prisms simultaneously. The loading values for different deflections were obtained until it reached the failure load of the prism, when the point load was carefully applied. Results of the block dry density are shown in Table 4.

\section{ANALYSIS OF RESULT AND DISCUSSION}

Harris [1] stipulated that the largest aggregate for cast earth should not be more than $10 \mathrm{~mm}$ and should contain all the sizes in significant quantities ranging from the highest to the lowest. The fine should constitute about $10 \%-20 \%$ of the total solid. To get a sample of the above specification was somewhat difficult, some samples from two different locations were mixed together and the result is shown below: Cast earth was subjected to compression under the compression testing machine. 40 samples were tested in which 20 samples were for $10 \%$ and $15 \%$ calcined gypsum with 7 and 14 days cure by sun drying. The 7 days cure for $10 \%$ and $15 \%$ recorded for the average compressive strength was 0.56 and $1.41 \mathrm{~N} / \mathrm{mm}^{2}$ respectively. The 14 days of sun dried specimens have average compressive strength of 1.24 and $1.61 \mathrm{~N} / \mathrm{mm}^{2}$ respectively. Typical examples of record tables are shown in Tables $\mathbf{5}$ and $\mathbf{6}$.

According to BS 6073 [8], the average compressive strength of 10 sandcrete blocks should not be less than the range $1.8-1.5 \mathrm{~N} / \mathrm{m}^{2}$ as the case may be. Though the average compressive strength obtained at $15 \%$ gypsum and less than the stipulated value by the BS 6073[8] but this value is adequate for a non-load bearing (infill) wall of residential building.

Table 7 showed the results of the compressive strength of sandcrete blocks, dry-cured for 28 days and were subjected to compressive tests and obtained from three major blockmaking industries in Ilorin (middle belt, Nigeria). Therefore, cast earth was better preferred to the block.

Table 4. Dry Density Results

\begin{tabular}{|c|c|c|c|c|c|c|}
\hline \multirow[t]{2}{*}{$\mathbf{S} / \mathbf{N}$} & $\mathbf{L}$ & B & $\mathbf{H}$ & DUW & \multirow[t]{2}{*}{$\mathrm{GV} \times 10^{5}\left(\mathrm{~mm}^{3}\right)$} & \multirow[t]{2}{*}{$\mathrm{DD} \times 10^{5}\left(\mathrm{Kg} / \mathrm{mm}^{3}\right)$} \\
\hline & \multicolumn{4}{|c|}{$(\mathbf{m m})$} & & \\
\hline 1 & 150 & 75 & 75 & 1.525 & 8.4 & 1.80 \\
\hline 2 & 150 & 75 & 75 & 1.512 & 8.4 & 1.79 \\
\hline 3 & 150 & 75 & 75 & 1.453 & 8.4 & 1.72 \\
\hline 4 & 150 & 75 & 75 & 1.464 & 8.4 & 1.74 \\
\hline 5 & 150 & 75 & 75 & 1.759 & 8.4 & 1.73 \\
\hline \multicolumn{6}{|c|}{ Average } & 1.76 \\
\hline
\end{tabular}


Table 5. Compressive Strength Test Results of $10 \%$ Gypsum Additive at 7 Days Curing

\begin{tabular}{|c|c|c|c|c|}
\hline Specimen No. & Sectional Area $\left(\mathbf{m m}^{2}\right)$ & Weight $(\mathbf{K g})$ & Failure Load $(\mathbf{K N})$ & Compr. Strength $\left(\mathbf{N} / \mathbf{m m}{ }^{2}\right)$ \\
\hline \hline 1 & 11,250 & 1.512 & 4.0 & 0.36 \\
\hline 2 & 11,250 & 1.510 & 6.0 & 0.53 \\
\hline 3 & 11,250 & $1.530 \mathrm{~S}$ & 0.53 \\
\hline 4 & 11,250 & 1.526 & 4.0 & 0.36 \\
\hline 5 & 11,250 & 1.509 & 8.0 & 0.71 \\
\hline 6 & 11,250 & 1.516 & 4.0 & 0.36 \\
\hline 8 & 11,250 & 1.486 & 6.0 & 0.0 \\
\hline 10 & 11,250 & 1.518 & 8.0 & 0.53 \\
\hline
\end{tabular}

Table 6. Compressive Strength Test Results of 15\% Gypsum Additive at 7 Days Curing

\begin{tabular}{|c|c|c|c|c|}
\hline Specimen No. & $\operatorname{Area}\left(\mathrm{mm}^{2}\right)$ & Weight (Kg) & Failure Load (KN) & Compr. Strength N/mm \\
\hline $1 \mathrm{~A}$ & 11,250 & 1.467 & 14.0 & 1.24 \\
\hline $3 \mathrm{~A}$ & 11,250 & 1.453 & 18.0 & 1.60 \\
\hline $4 \mathrm{~A}$ & 11,250 & 1.525 & 18.0 & 1.60 \\
\hline $6 \mathrm{~A}$ & 11,250 & 1.498 & 18.0 & 1.60 \\
\hline $8 \mathrm{~A}$ & 11,250 & 1.504 & 14.0 & 1.24 \\
\hline $9 \mathrm{~A}$ & 11,250 & 1.478 & 16.0 & 1.42 \\
\hline $10 \mathrm{~A}$ & 11,250 & 1.495 & 16.0 & 1.42 \\
\hline
\end{tabular}

Table 7. Compressive ( Compr.) Strength of Commercially Produced Sandcrete Blocks

\begin{tabular}{|c|c|c|c|c|}
\hline \multirow{2}{*}{ Place of Purchase in Ilorin (Nigeria) } & \multicolumn{2}{|c|}{ Sample 1 } & \multicolumn{2}{c|}{ Sample 2 } \\
\cline { 2 - 5 } & Failure Load (kN) & Compr. Strength (N/mm $\left.{ }^{2}\right)$ & Failure Load (kN) & Compr. Strength (N/nn $\left.{ }^{2}\right)$ \\
\hline \hline O'Block Industry, Sango, Ilorin & 62 & 1.13 & 60 & 1.09 \\
\hline L'Block Industry, Ajasse-Ipo Road, Ilorin & 54 & 0.98 & 58 & 1.05 \\
\hline S'Block Industry, Asa-Dam Road Ilorin & 44 & 0.8 & 52 & 0.95 \\
\hline
\end{tabular}

Source [9].

\section{FLEXURAL STRENGTH TEST AND RESULTS (Table 8)}

SPECIMEN SPAN: $\quad 120 \mathrm{~mm}$

\section{PRE TEST TYPE: $\quad 3$ POINT}

FLEXURAL-LOAD: OFF

TEST SPEED: $\quad 010.00 \mathrm{~mm} / \mathrm{min}$.

Cast earth was subjected to the universal testing machine for the purpose of determining the flexural strength. The 3point flexural was used and the results shown in Table 8 .

\section{CONCLUSION}

From the research work carried out on cast laterite, the following can be inferred that:

The mixture of laterite and calcined gypsum is viable for wall construction but setting time was observed retarded. The comparison of the tests results indicates that cast laterite of $15 \%$ gypsum additive is adequate and higher in compression and flexure than the sandcrete blocks (common walling material in Nigeria). Cast laterite attains to the compressive 
Table 8. Result of Flexural Strength Test

\begin{tabular}{|c|c|c|c|c|c|}
\hline Test No. & Width $(\mathbf{m m})$ & Thickness $(\mathbf{m m})$ & Load @Peak (N) & Def.@Peak (mm) & Stress @Peak (N/mm $\left.{ }^{2}\right)$ \\
\hline \hline 1 & 75.00 & 75.00 & 1652.4 & 1.904 & 0.7050 \\
\hline 2 & 75.00 & 75.00 & 2804.5 & 2.5300 & 1.1966 \\
\hline 3 & 75.00 & 75.00 & 1568.9 & 1.4280 & 0.6694 \\
\hline 4 & 75.00 & 75.00 & 1830.8 & 1.1370 & 0.7811 \\
\hline Minim. & 75.00 & 75.00 & 1568.9 & 1.7498 & 0.6694 \\
\hline Mean & 75.00 & 75.00 & 1964.1 & 2.5300 & 0.8380 \\
\hline Maxim. & 75.00 & 75.00 & 2804.5 & 0.6087 & 1.1966 \\
\hline Standard. Deviation (SD) & 0.00 & 0.00 & 570.8 & 0.2435 \\
\hline
\end{tabular}

\begin{tabular}{|c|c|c|c|c|c|}
\hline Test No & Energy @ Peak (N.m) & Load @Yield (N) & Def. @ Yield (mm) & Bending Strength @Yield (N/mm $\mathbf{m}^{2}$ & Bending Modulus (N/mm $\left.^{2}\right)$ \\
\hline \hline 1 & 1.2369 & 606.20 & 0.9910 & 0.2586 & 14.32 \\
\hline 2 & 2.5948 & - & - & - & 20.49 \\
\hline 3 & 0.8888 & 593.70 & 0.7380 & 0.2533 & 17.39 \\
\hline 4 & 0.8290 & 610.60 & 0.5710 & 0.2605 & 32.39 \\
\hline Minim & 0.8290 & 593.70 & 0.5710 & 0.2533 & 14.32 \\
\hline Mean & 1.3874 & 603.50 & 0.7667 & 0.2575 & 21.20 \\
\hline Maxi & 2.5948 & 610.60 & 0.9910 & 0.2605 & 32.62 \\
\hline SD & 0.8248 & 8.77 & 0.2115 & 0.0037 & 8.01 \\
\hline
\end{tabular}

strength of a residential building wall at 14 days. The average compressive strength for $15 \%$ calcined gypsum was 1.21 $\mathrm{N} / \mathrm{mm}^{2}$. The compressive strength of sandcrete blocks, drycured for 28 days which were obtained from three major block-making industries in Ilorin (middle belt, Nigeria) clearly showed that cast earth wall was better preferred to the sandcrete block wall. The wall deflection results vary with the percentage of gypsum additives in the laterite soil. At peak value, maximum deflection is $2.53 \mathrm{~mm}$.

\section{REFERENCES}

[1] L. A. Harris, available "http://www.greenhomebuilding.com", 2002.

[2] L. O. Abdulkareem, "Investigation of strength and durability of walls built of traditional laterite materials", A final year project submitted to the Department of Civil Engineering, University of Ilorin, 1988, pp. 5-7.

[3] D. A. Medubu, "Structural design of a two storey and blockwall residential building", A final year project submitted to the Department of Civil Engineering, University of Ilorin, 1995, pp. 1-53.
[4] A. B. Laisi, "Effect of gain size on strength cubes made from laterite soils", Int. J. Dev. Technol. vol. 4, no. 3, pp. 137-139, 1986.

[5] L. S. Blake, Civil Engineer's Reference Book, $4^{\text {th }}$ Ed, McMillan, 1989.

[6] BS 5628-1: 2005, "Code of practice for the use of masonry. Structural use of unreinforced masonry", BSi Committee: B/525/6, pp. 80.

[7] BS 1610-1: 1992, "Materials testing machines and force verification equipment. Specification for the grading of the forces applied by materials testing machines when used in the compression mode", BSi Committee: ISE/NFE/4, pp. 16

[8] British Standards Institution BS 6073: "Precast concrete masonry unit" Part 1: "Specification for precast masonry units", BSI, London. pp. 1-11, 1981.

[9] BS 410:1986, "Specification for test sieves", BSi Committee: LBI/37, pp. 24.

[10] A. A. Situ, "A simple device to determine the compressive strength of sandcrete block", A final year project submitted to the Department of Civil Engineering, University of Ilorin, 1998, pp. 1-49. 